\title{
DESEMPENHO DE FAMILIAS DO CRUZAMENTO ENTRE LINHAGENS DE FEIJÕES ANDINOS E MESOAMERICANOS EM PRODUTIVIDADE E RESISTÊNCIA A Phaeoisariopsis griseola
}

\author{
Performance of common bean families from cross between of andean and mesoamerica lines on \\ grain yield and resistance to Phaeoisariopsis griseola
}

\author{
Adriano Teodoro Bruzi ${ }^{1}$, Magno Antonio Patto Ramalho ${ }^{2}$, Ângela de Fátima Barbosa Abreu ${ }^{3}$
}

\begin{abstract}
RESUMO
No Estado de Minas Gerais, tem sido constatado que as raças fisiológicas prevalecentes de Phaeiosariopsis griseola (Sacc.) Ferr. infectam predominantemente os feijões mesoamericanos. Os feijões andinos normalmente apresentam boa resistência. A introdução de alelos de resistência de cultivares andinas em cultivares mesoamericanas é uma boa estratégia na obtenção de cultivares adaptadas e resistentes a esse patógeno. Com esse objetivo foi realizado o cruzamento entre a linhagem ESAL 550 (grupo andino e resistente à mancha angular) x Carioca-MG (grupo mesoamericano e suscetível à mancha angular). Após a avaliação das famílias segregantes nas gerações $\mathrm{F}_{2: 3}, \mathrm{~F}_{2: 4}$ e $\mathrm{F}_{2: 5}$, foram selecionadas linhagens que associavam bom nível de resistência à $P$. griseola e grãos creme com rajas marrons porém, nenhum deles em condições de ter aceitação comercial.
\end{abstract}

Termos para indexação: Resistência à mancha angular, melhoramento genético, herdabilidade.

\begin{abstract}
In some regions of Minas Gerais State, prevalent physiological races of Phaeoisariopsis griseola (Sacc.) Ferr. infect mainly cultivars of Mesoamerican origin, but the Andean cultivars are resistant. The introduction of alleles for resistance of Andean cultivars in Mesoamerican cultivars is a good strategy to obtain adapted cultivars with resistance to this disease. With this purpose, the cross between ESAL 550 (Andean group and resistant to angular leaf spot) and Carioca-MG (Mesoamerican group and susceptible to angular leaf spot) was performed. After evaluation of the segregant families in generations $\mathrm{F}_{2: 3}, \mathrm{~F}_{2: 4}$ and $\mathrm{F}_{2: 5}$, some lines with high resistance to $P$. griseola and grain type far from market standard were identified.
\end{abstract}

Index terms: Resistance to angular leaf spot, genetics breeding, heritability.

\section{(Recebido em 23 de março de 2005 e aprovado em 16 de fevereiro de 2006)}

\section{INTRODUÇÃO}

Entre os fenótipos desejáveis de uma nova cultivar de feijão (Phaseolus vulgaris L.), está um bom nível de resistência a Phaeoisariopsis griseola agente causal da mancha angular. Isso porque, esse patógeno, especialmente sob condições de alta umidade e temperatura moderada associado à presença precoce do inóculo, acarreta perdas expressivas na produtividade de grãos (SARTORATO \& RAVA, 1994).

A principal alternativa de controle é por meio de cultivares resistentes (CARVALHO et al., 1998; FERREIRA et al., 1999; NIETSCHE et al., 1997, 1998, 1999). Contudo esse patógeno possui várias raças fisiológicas, o que dificulta o trabalho dos melhoristas (NIETSCHIE, 2000; SARTORATO, 2002). Tem sido constatado na América Latina que os fenótipos de virulência de $P$. griseola podem ser separados de acordo com a região de origem, que pode ser andina ou mesoamericana, evidenciando uma coevolução do patógeno e hospedeiro (CORRALES \& JARA, 1995).

Em algumas regiões do Estado de Minas Gerais, tem sido constatado que as raças prevalecentes de $P$. griseola infectam predominantemente os feijões mesoamericanos. Tanto é assim que linhagens andinas, tais como feijões amarelos e grandes do grupo Jalo, manifestam poucos sintomas da doença. Contudo, a utilização de cultivares andinas como fonte de resistência a esse patógeno nem sempre é possível devido à ocorrência de incompatibilidade na hibridação entre algumas combinações de feijões andinos e mesoamericanos que se manifesta impedindo o desenvolvimento e crescimento da geração $\mathrm{F}_{1}$ (SINGH \& GUTIÉRREZ, 1984; VIEIRA et al., 1989). O controle genético dessa incompatibilidade tem sido explicado pela presença de dois genes $\left(\mathrm{Dl}_{1}\right.$ e $\left.\mathrm{Dl}_{2}\right)$ com

\footnotetext{
Engenheiro Agrônomo, Msc. Genética e Melhoramento de Plantas - Departamento de Biologia/DBI - Universidade Federal de Lavras/UFLA Cx. P. 3037 - 37.200-000 - Lavras, MG - atbruzi@yahoo.com.br

${ }^{2}$ Dr. Genética e Melhoramento de Plantas - Professor Titular do Departamento de Biologia/DBI - Universidade Federal de Lavras/UFLA - Cx. P. 3037 37.200-000 - Lavras, MG - magnoapr@ufla.br

Dra. Genética e Melhoramento de Plantas, Pesquisadora EMBRAPA Arroz e Feijão - afbabreu@ufla.br
} 
epistasia recessiva dupla (SHII et al., 1980). As cultivares andinas possuem o genótipo $\mathrm{dl}_{1} \mathrm{dl}_{1} \mathrm{Dl}_{2} \mathrm{Dl}_{2} \mathrm{e}$ as mesoamericanas $\mathrm{Dl}_{1} \mathrm{Dl}_{1} \mathrm{dl}_{2} \mathrm{dl}_{2}$. A ocorrência dos alelos dominantes dos dois genes acarreta a incompatibilidade $\mathrm{e}$ o cruzamento só será possível se uma ou ambas cultivares apresentarem a constituição $\mathrm{dl}_{1} \mathrm{dl}_{1} \mathrm{dl}_{2} \mathrm{dl}_{2}$.

Entre as cultivares do tipo mesoamericano, a Carioca-MG apresenta boa produtividade e porte ereto, entretanto possui grãos pequenos e suscetibilidade à $P$. griseola. Essa cultivar ao que tudo indica tem o genótipo $\mathrm{dl}_{1} \mathrm{dl}_{1} \mathrm{dl}_{2} \mathrm{dl}_{2} \mathrm{e}$, portanto pode ser hibridizada com cultivares andinas (BRUZI et al., 2003). Dessa forma este trabalho teve por objetivo selecionar famílias que associem tipo de grãos carioca de bom tamanho, boa produtividade e resistência à P. griseola a partir do cruzamento CariocaMG com ESAL 550, linhagem do grupo andino.

\section{MATERIAL E MÉTODOS}

Os trabalhos foram conduzidos no Departamento de Biologia da Universidade Federal de Lavras, situada no Sul do Estado de Minas Gerais a 980,20 m de altitude, $21^{\circ} 14^{\prime} \mathrm{S}$ de latitude e $40^{\circ} 17^{\prime} \mathrm{W}$ de longitude. A precipitação média anual é de $1529,7 \mathrm{~mm}$, a temperatura média de $19,14^{\circ} \mathrm{C}$ e a umidade relativa do ar $76,2 \%$.

Como já mencionado as famílias utilizadas nesse trabalho foram provenientes do cruzamento entre as linhagens Carioca-MG e ESAL 550. A 'Carioca-MG' possui grãos de cor creme com rajas marrom-escuras, peso de cem sementes de 20 a $22 \mathrm{~g}$, porte ereto e suscetibilidade à mancha angular. Já a linhagem ESAL 550, possui grãos amarelos grandes, peso de cem grãos de $50 \mathrm{~g}$ e resistência à $P$. griseola.

No ano de 2001, foram obtidas as sementes $F_{1}$ e $F_{2}$ e posteriormente as famílias $\mathrm{F}_{2: 3}$. Em fevereiro de 2002, foram avaliadas 194 famílias $\mathrm{F}_{2: 3}$ mais os dois genitores. $\mathrm{O}$ delineamento utilizado foi um látice simples 14 x 14 e parcelas de uma linha de um metro. A semeadura foi realizada em plantio direto em rotação com a cultura do milho. O espaçamento entre linhas foi de $0,5 \mathrm{~m}$ com 15 sementes por metro. A adubação foi equivalente a $300 \mathrm{~kg} /$ ha da fórmula 8-28-16 de $\mathrm{N}, \mathrm{P}_{2} \mathrm{O}_{5}$ e $\mathrm{K}_{2} \mathrm{O}$ mais $\mathrm{Zn}$. Em cobertura foi aplicado $150 \mathrm{~kg} / \mathrm{ha}$ de sulfato de amônio. A cultura foi submetida à irrigação por aspersão sempre que necessário. Durante o ciclo da cultura não se fez uso de defensivo agrícola.

Foi avaliada a severidade da mancha angular por meio de uma escala de notas com nove graus de severidade proposta pelo CIAT e adaptada por Nietschie (2000), aproximadamente 15 dias antes da colheita. Também foi considerada a produtividade média de grãos.
Das 194 famílias $\mathrm{F}_{2: 3}$ foram selecionaram-se 98 famílias que apresentaram notas de severidade de $P$. griseola inferior a 4. Na safra de outono-inverno, de 2002, as famílias $\mathrm{F}_{2: 4}$ foram semeadas em julho e avaliadas junto com os dois genitores . O delineamento foi látice triplo 10 x 10 e as parcelas de duas linhas de dois metros. Deve-se salientar que não foi possível efetuar avaliação da severidade da mancha angular, pois a doença não ocorreu durante o cultivo. Em função da produtividade foram selecionadas 62 famílias apresentavam grãos tipo carioca, que, na geração $\mathrm{F}_{2: 5}$, foram novamente avaliadas na safra da seca de 2003, semeadura no mês de Fevereiro. O delineamento foi látice triplo $8 \times 8$ e parcelas de duas linhas de dois metros. Foram avaliadas a severidade da mancha angular e a produtividade média de grãos.

Os dados de produtividade de grãos e notas de severidade de $P$. griseola foram inicialmente submetidos à análise de variância individual. A partir das esperanças dos quadrados médios, foi estimada a variância genética por geração i $\left(\sigma_{\mathrm{Gi}}^{2}\right)$, bem como o seu intervalo de confiança (RAMALHO et al., 2005). Estimou-se também a herdabilidade no sentido amplo na geração $i\left(h_{i}^{2}\right)$, para a seleção na média das famílias. O intervalo de confiança de $\left(h_{1}^{2}\right)$ foi obtido conforme Knapp et al. (1985).

Posteriormente, utilizando as médias ajustadas das 62 famílias comuns às três gerações, realizou-se a análise da variância conjunta para produtividade de grãos (RAMALHO et al., 2005). Considerando que o efeito de famílias foi aleatório e de gerações fixo, para estimar a variância genética entre as 62 famílias comuns as três gerações, estimou-se a covariânca do desempenho médio das famílias nas gerações duas a duas. A média dessas covariâncias corresponde à variância genética comum as três gerações (SILVA, 2003).

\section{RESULTADOS E DISCUSSÃO}

Um dos motivos que podem ter levado muitas vezes aos melhoristas não analisarem as avaliações da incidência ou severidade de doenças deriva do fato de que tais dados podem não atender às pressuposições básicas da análise da variância (RAMALHO et al., 2005). Contudo, na cultura do feijoeiro, Marques Júnior (1997), observou que não houve maiores restrições em proceder à análise da variância para notas de severidade da doença. Por essa razão foram realizadas as análises da variância das notas de severidade da mancha angular das gerações individuais, bem como das 62 famílias comuns às gerações $\mathrm{F}_{2: 3}$ e $\mathrm{F}_{2: 5}$.

Constatou-se diferença significativa quanto à severidade de doença $(\mathrm{P} \leq 0,01)$ entre as famílias nas duas 
gerações individuais, evidenciando assim a existência de variabilidade. A cultivar suscetível Carioca-MG, por exemplo, recebeu nota 6,0. O genitor do grupo andino ESAL 550 praticamente não manifestou sintomas da doença. Embora, ocorresse variação entre as famílias em todos os casos a severidade média do patógeno nas famílias foi inferior a 'Carioca-MG'.

O intervalo de confiança das estimativas da variância genética $\left(\sigma_{G i}^{2}\right)$ entre as famílias para as notas de mancha angular evidenciam que esta foi diferente de zero confirmando a existência de variabilidade. A possibilidade de sucesso com a seleção, para o caráter, é evidenciada pelas estimativas da herdabilidade $\left(h_{j}^{2}\right)$ para seleção na média das famílias. Os valores de $h_{i}^{2}$ foram relativamente altos, e com $95 \%$ de probabilidade, diferente de zero (Tabela 1).

Quando se realizou a análise conjunta considerando apenas as 62 famílias comuns às gerações $\mathrm{F}_{2: 3}$ e $\mathrm{F}_{2: 5}$ não se detectou diferença significativa entre elas, indicando assim desempenho semelhante para notas de severidade do patógeno. A pequena magnitude das estimativas da variância genética (Tabela 2) confirma essa observação. Comprova-se assim que a seleção na geração $F_{2: 3}$ para a resistência à mancha angular foi eficiente, pois possibilitou a obtenção de famílias $\mathrm{F}_{2.5}$ como bom nível de resistência.
Para produtividade de grãos observou-se diferença significativa entre as famílias nas análises individuais. A amplitude de variação no desempenho médio das famílias nas três gerações realça também, a existência de variabilidade. Nas gerações $\mathrm{F}_{2: 4}$ e $\mathrm{F}_{2: 5}$ a média das famílias foi inferior a dos genitores (Tabela 1). Entretanto, foram identificadas famílias com desempenho superior a ambos os pais. As estimativas da variância genética entre famílias $\left(\sigma_{G i}^{2}\right)$ apresentadas na Tabela 1 confirmam também essa observação. Nas três gerações o limite inferior $\sigma_{G i}^{2}$ foi positivo, indicando, com $95 \%$ de probabilidade, que as estimativas da $\left(\sigma_{G i}^{2}\right)$ foram diferentes de zero. As estimativas da $h_{i}^{2}$ variaram entre as gerações sendo menor na geração $\mathrm{F}_{2: 4}$. Muito embora essa herdabilidade seja no sentido amplo, a participação da variância de dominância $\left(\sigma_{D}^{2}\right)$ é muito pequena. Isso porque a variância genética entre famílias $\mathrm{F}_{2: 3}\left(\sigma_{G}^{2}\right)$ contém $\sigma_{G_{2: 3}}^{2}=\sigma_{A}^{2}+(1 / 4) \sigma_{D}^{2}$ em que $\sigma_{A}^{2}$ é a variâncián genética aditiva. Já a $\sigma_{G_{2 \cdot 4}}^{2}=\sigma_{A}^{2}+(1 / 16) \sigma_{D}^{2} \mathrm{e}$ $\sigma_{G_{2: 5}}^{2}=\sigma_{A}^{2}+(1 / 64) \sigma_{D}^{2}$ (SOUZAJÚNIOR, 1989). Os valores obtidos são semelhantes às estimativas apresentadas na literatura envolvendo a avaliação de famílias, porém, considerando apenas cruzamentos entre feijões mesoamericanos (ABREU et al., 2002; CARNEIRO et al., 2002; SANTOS et al., 2001; SILVA, 2003).

TABELA 1 - Estimativas dos parâmetros genéticos e fenotípicos para notas de severidade da mancha angular e produtividade de grãos em $\left(\mathrm{g} / 2 \mathrm{~m}^{2}\right)$ obtidos na avaliação das famílias $\mathrm{F}_{2: 3}, \mathrm{~F}_{2: 4} \mathrm{eF}_{2: 5}$ do cruzamento das linhagens de feijão Carioca-MG x ESAL 550.

\begin{tabular}{|c|c|c|c|c|c|}
\hline & $\mathbf{F}_{2: 3}$ & $\mathbf{F}_{2: 3}$ & $\mathbf{F}_{2: 4}$ & $\mathbf{F}_{2: 5}$ & $\mathbf{F}_{2: 5}$ \\
\hline & $\begin{array}{l}\text { Produtividade de } \\
\text { Grãos }\end{array}$ & $\begin{array}{l}\text { Mancha } \\
\text { Angular }\end{array}$ & $\begin{array}{c}\text { Produtividade de } \\
\text { Grãos }\end{array}$ & $\begin{array}{c}\text { Produtividade de } \\
\text { Grãos }\end{array}$ & $\begin{array}{l}\text { Mancha } \\
\text { Angular }\end{array}$ \\
\hline $\begin{array}{l}\text { Número de } \\
\text { Famílias }\end{array}$ & 194 & 194 & 98 & 62 & 62 \\
\hline $\begin{array}{c}\text { Variância } \\
\operatorname{Genética}\left(\sigma_{\mathrm{G}}^{2}\right)\end{array}$ & $\begin{array}{c}1041,77 \\
(853,50-1285,40)^{1 /}\end{array}$ & $\begin{array}{c}1,89 \\
(1,56-2,32)^{1 /}\end{array}$ & $\begin{array}{c}1163,74 \\
(897,10-1570,50)^{1 /}\end{array}$ & $\begin{array}{c}4937,81 \\
(3582,60-7242,40)^{1 /}\end{array}$ & $\begin{array}{c}0,19 \\
(0,14-0,28)^{1 /}\end{array}$ \\
\hline $\begin{array}{l}\text { Herdabilidade } \\
h^{2} \%\end{array}$ & $\begin{array}{c}66,0 \\
(54,00-74,00)^{1 /}\end{array}$ & $\begin{array}{c}47,0 \\
(28,90-60,10)^{1 /}\end{array}$ & $\begin{array}{c}26,0 \\
(-3,00-48,00)^{1 /}\end{array}$ & $\begin{array}{c}74,0 \\
(59,0-83,0)^{1 /}\end{array}$ & $\begin{array}{c}40,98 \\
(9,05-62,65)^{1 /}\end{array}$ \\
\hline $\begin{array}{l}\text { Média das } \\
\text { Famílias }\end{array}$ & $\begin{array}{c}441,4 \\
(165,60-1003,70)^{1 /}\end{array}$ & $\begin{array}{c}3,65 \\
(1,00-9,00)^{1 /}\end{array}$ & $\begin{array}{c}473,7 \\
(344,50-622,50)^{1 /}\end{array}$ & $\begin{array}{c}393,9 \\
(264,80-578,70)^{1 /}\end{array}$ & $\begin{array}{c}2,38 \\
(2,55-5,08)^{1 /}\end{array}$ \\
\hline CV\% & 29,80 & 33,60 & 20,50 & 18,10 & 18,96 \\
\hline \multicolumn{6}{|l|}{$\begin{array}{l}\text { Média dos } \\
\text { Genitores }\end{array}$} \\
\hline Carioca-MG & 415,00 & 6,00 & 539,30 & 548,30 & 6,84 \\
\hline ESAL 550 & 262,80 & 1,00 & 482,70 & 438,40 & 2,40 \\
\hline
\end{tabular}

${ }^{1 /}$ Limite inferior e superior da estimativa, no nível de $5 \%$ de probabilidade.

Ciênc. agrotec., Lavras, v. 31, n. 3, p. 650-655, maio/jun., 2007 
TABELA 2 - Estimativas dos componentes da variância genética, fenotípica e da interação genótipos de feijões $\mathrm{x}$ ambientes para notas de severidade da mancha angular das 62 famílias comuns nas gerações $F_{2.3}$ e $F_{2.5}$ do Cruzamento das linhagens Carioca-MG x ESAL 550.

\section{Parâmetros \\ Estimativas}

\begin{tabular}{lc}
\hline Variância Genética $\left(\sigma_{\mathrm{G}_{\mathrm{F}_{2: 3}}}^{2}\right)$ & 0,12 \\
Variância Genética $\left(\sigma_{\mathrm{G}_{\mathrm{F}_{2: 5}}}^{2}\right)$ & 0,04 \\
Covariância $\left(\mathrm{Cov}_{\mathrm{F}_{2: 3} / \mathrm{F}_{2: 5}}\right)$ & 0,03 \\
Variância Genética da & 0,01 \\
Interação $\left(\sigma_{\mathrm{G} \text { x A }}^{2}\right)$ & 2,19 \\
Média & $25,77(-23,18-55,27)^{1 /}$ \\
Herdabilidade $\left(\mathrm{h}^{2} \%\right)$ &
\end{tabular}

${ }^{1 /}$ Limite inferior e superior da estimativa, respectivamente, no nível de $5 \%$ de probabilidade.
As estimativas dos parâmetros genéticos e fenotípicos envolvendo as 62 famílias comuns as três gerações, para produtividade de grãos é apresentada na Tabela 3. A mais provável razão para a diferença na magnitude das estimativas dos parâmetros genéticos seja a interação famílias x gerações que é frequiente na cultura do feijoeiro na região sul de Minas Gerais (ABREU et al., 1990; RAMALHO et al., 1998; SILVA, 2003). No presente trabalho, foi detectada a existência de interação famílias $\mathrm{x}$ gerações e seu componente $\left(\sigma_{G x A}^{2}\right)$ foi de magnitude semelhante à variância genética. A herdabilidade na média das três gerações foi superior a 35\%, valor esse comparável ao relatado por Silva (2003).

Os feijões foram classificados por Singh et al. (1991) em função do tipo de faseolina, tamanho de grãos e outros caracteres em seis raças. Há relatos de que maior capacidade de combinação é esperada no cruzamento entre genitores de diferentes raças (ABREU et al., 1999; NIENHUIS \& SINGH, 1988; SINGH \& URREA, 1995). Na presente situação o cruzamento foi entre uma cultivar da raça mesoamericana, a Carioca-MG, e uma da raça Nova Granada (Andina), a ESAL 550. A hibridação entre feijões

TABELA 3 - Estimativas dos componentes da variância genética, fenotípica e da interação genótipos de feijões x ambientes da produtividade de grãos $\mathrm{g} / 2 \mathrm{~m}^{2}$ das 62 famílias comuns nas gerações $\mathrm{F}_{2: 3}, \mathrm{~F}_{2: 4}$ e $\mathrm{F}_{2: 5}$ do Cruzamento das linhagens Carioca-MG x ESAL 550.

\begin{tabular}{|c|c|}
\hline Parâmetros & Estimativas \\
\hline Variância Genética $\left(\sigma_{G_{F_{223}}}^{2}\right)$ & 5880,80 \\
\hline Variância Genética $\left(\sigma_{G_{F 2: 4}}^{2}\right)$ & 42,31 \\
\hline Variância Genética $\left(\sigma_{G_{F_{2: 5}}}^{2}\right)$ & 4649,30 \\
\hline $\operatorname{Cov}_{\mathrm{F}_{2: 3} / \mathrm{F}_{2: 4}} 2 /$ & 2169,40 \\
\hline $\operatorname{Cov}_{F_{2: 3} / F_{2: 5}}{ }^{2 /}$ & 1580,90 \\
\hline $\operatorname{Cov}_{F_{2: 4} / F_{2: 5}}{ }^{2 /}$ & 32,50 \\
\hline Covariância Média $\left(\operatorname{Cov}_{M}\right)$ & 1260,90 \\
\hline Variância Genética da Interação $\left(\sigma_{\mathrm{G} \text { x A }}^{2}\right)$ & 1261,70 \\
\hline Média & $462,80(373,00-602,30)^{1 /}$ \\
\hline Herdabilidade $\left(\mathrm{h}^{2} \%\right)$ & $35,9(2,30-59,30)^{1 /}$ \\
\hline
\end{tabular}


andinos e mesoamericanos, normalmente, não é possível, pois devido à ocorrência de incompatibilidade que se manifesta nas plantas $F_{1}$. É importante enfatizar que informações mais recentes (VILARINHO, 2004) evidenciam que o controle genético da incompatibilidade é provavelmente diferente do que foi preconizado por Shii et al. (1980). A produção de uma população segregante com média alta e grande variabilidade era esperado no presente trabalho. Contudo, Jonhson \& Gepts (2002) enfatizam que feijões mesoamericanos e andinos, por serem domesticados em regiões bem distintas desenvolveram complexos gênicos específicos e interações epistáticas particulares. Quando cruzadas essas combinações são desfeitas e dificilmente obtêmse linhagens promissoras. Em trabalho desenvolvido por Abreu et al. (1999), foram realizados três cruzamentos entre a cultivar da raça mesoamericana Carioca e cultivares da raça Nova Granada (Andina). Desses apenas um foi compatível, a Carioca x Perry Marrow. Nesse caso a média da população obtida foi $28,9 \%$ inferior a média das populações que envolviam cruzamentos de feijões mesoamericanos $x$ mesoamericanos. Esse comportamento inferior do híbrido foi atribuído ao fato de que a linhagem da raça Nova Granada não era adaptada à região.

No cruzamento realizado, 'Carioca-MG' x 'ESAL 550' ambos os genitores são adaptados, pois foram selecionados no programa de melhoramento conduzido na região. Por essa razão, provavelmente, não se constataram resultados semelhantes aos apresentados por Abreu et al. (1999). A população segregante apresentou média alta e variabilidade para se antever sucesso com a seleção. Contudo, uma dificuldade observada foi à ampla segregação obtida para tipo de grãos. Esses variaram na cor, no formato e no peso o que está de acordo com a observação de Jonhson \& Gepts (2002).

\section{CONCLUSÕES}

Foi possível selecionar famílias com boa produtividade de grãos e resistência à mancha angular, contudo, com tipo de grãos fora do padrão comercial carioca.

\section{REFERÊNCIAS BIBLIOGRÁFICAS}

ABREU, A. de F. B.; RAMALHO, M. A. P.; FERREIRA, D. F. Selection potential for seed yield from intra and inter racial populations in common bean. Euphytica, Wageningen, v. 108, p. 121-127, 1999.
ABREU, A. de F. B.; RAMALHO, M. A. P.; SANTOS, J. B. dos. Prediction of seed-yield potential of common bean populations. Revista Brasileira de Genética, Ribeirão Preto, v. 25, p. 323-327, 2002.

ABREU, A. de F. B.; RAMALHO, M. A. P.; SANTOS, J. B. dos; PEREIRA FILHO, I. A. Effect of genotype on estimation of genetic and phenotypic parameters of common beans. Revista Brasileira de Genética, Ribeirão Preto, v. 13, p. 7582, 1990.

BRUZI, A. T.; RAMALHO, M. A. P.; ABREU, A. de F. B. Melhoramento visando a resistência a mancha angular utilizando cultivares de raças andinas e mesoamericanas de feijão: I. avaliação de famílias segregantes do cruzamento ESAL 550 x Carioca-MG. In: CONGRESSO DE INICIAÇÃO CIENTÍFICA, 2003, Lavras. Resumos... Lavras: UFLA, 2003.

CARNEIRO, J. E. de S.; RAMALHO, M. A. P.; ABREU, A. de F. B.; GONÇALVES, F. M. A. Breeding potential of single, double and multiple crosses in common bean. Crop Breeding and Applied Biotechnology, Londrina, v. 2, n. 4, p. 515-524, 2002.

CARVALHO, G. A.; PAULA JÚNIOR, T. J.; ALZATEMARIN, A. L.; NIETSCHE, S.; BARROS, E. G.; MOREIRA, M. A. Herança da resistência da linhagem AND-277 de feijoeiro comum à raça 63-23 de Phaeoisariopsis griseola e identificação de marcador RAPD ligado ao gene de resistência. Revista Ceres, Viçosa, v. 23, n. 4, p. 482-485, 1998.

CORRALES, M. A.; JARA, C. A. La evolución de Phaeoisariopsis griseola com el frijol común en América Latina. Fitopatologia Colombiana, [S.1.], v. 19. p. 15-22, 1995.

FERREIRA, C. F.; BORÉM, A.; CARVALHO, G. A.; NIETSCHE, S.; PAULA JÚNIOR, T. J.; BARROS, E. G.; MOREIRA, M. A. Herança da resistência do feijoeiro à mancha angular. Fitopatologia Brasileira, Brasília, v. 24, n. 3, p. 391-393, 1999.

JONHSON, W. C.; GEPTS, P. The role of epistasis in controlling seed yield and other agronomic traits in an Andean x Mesoamerican cross of common bean (Phaseolus vulgaris). Euphytica, Wageningen, v. 125, p. 69-79, 2002. 
KNAPP, S. J.; STROUP, W. W.; ROSS, W. M. Exact confidence intervals for heritability on a progeny mean basis. Crop Science, Madison, v. 25, n. 1, p. 192-194, Jan./Feb. 1985.

MARQUES JÚNIOR, O. G. Eficiência de experimentos com a cultura do feijão. 1997. 80 f. Tese (Doutorado) Universidade Federal de Lavras, Lavras, 1997.

NIENHUIS, J.; SINGH, S. P. Genetic of seed yield and its components in common bean (Phaseolus vulgaris L.) of middle-americam origins: I. general combining ability. Plant Breending, Cambrige, v. 101, n. 2, p. 143-154, June 1988.

NIETSCHE, S. Mancha angular do feijoeiro comum: variabilidade genética do patógeno e identificação de marcadores moleculares ligados a identificação de raças de Phaeoisariopsis griseola e determinação de à resistência. 2000. 56 f. Tese (Doutorado em Genética e Melhoramento de Plantas) - Universidade Federal de Viçosa, Viçosa, 2000.

NIETSCHE, S.; BORÉM, A.; CARVALHO, G. A.; PAULA JÚNIOR, T. J.; BARROS, E. G.; MOREIRA, M. A. Fontes de resistência à mancha angular do feijoeiro em Minas Gerais. Revista Ceres, Viçosa, v. 45, n. 262, p. 567-571, 1998.

NIETSCHE, S.; BORÉM, A.; FERREIRA, C. F.; CARVALHO, G. A.; PAULA JÚNIOR, T. J.; BARROS, E. G.; MOREIRA, M. A. Caracterização de patótipos de Phaeoisariopsis griseola através da utilização de folhas enraizadas de feijoeiro. Fitopatologia Brasileira, Brasília, v. 24, n. 4, p. 549-551, 1999.

NIETSCHE, S.; CARVALHO, G. A.; BORÉM, A.; PAULA JÚNIOR, T. J.; FERREIRA, C.; BARROS, E. G; MOREIRA, M. A. Variabilidade patogênica de Phaeoisariopsis griseola em Minas Gerais. Fitopatologia Brasileira, Brasília, v. 22, p. 289, 1997.

RAMALHO, M. A. P.; ABREU, A. de F. B.; SANTOS, P. S. J. dos. Interação genótipos x épocas de semeadura, anos e locais na avaliação de cultivares de feijão nas regiões Sul e Alto Paranaíba em Minas Gerais. Ciência e Agrotecnologia, Lavras, v. 22, p. 301-307, 1998.

RAMALHO, M. A. P.; FERREIRA, D. F.; OLIVEIRA, A. C. de. A experimentação em genética e melhoramento de plantas. Lavras: UFLA, 2005. 326 p.

SANTOS, V. da S.; RAMALHO, M. A. P.; CARNEIRO, J. E. de S.; ABREU, A. de F. B. Consequences of early selection for grain type in common bean breeding. Crop Breeding and Applied Biotechnology, Londrina, v. 1, n. 4, p. 347-354, 2001.

SARTORATO, A. Identification of Phaeoisariopsis griseola pathotypes from five states in Brazil. Fitopatologia Brasileira, Brasília, v. 27, n. 1, p. 78-81, 2002.

SARTORATO, A.; RAVA, C. A. Principais doenças do feijoeiro comum e seu controle. Brasília, DF: Embrapa, 1994. $300 \mathrm{p}$.

SHII, C. T.; MOK, M. C.; TEMPLE, S. R.; MOK, D. W. S. Expression of developmental abnormalities in hibrids of Phaseolus vulgaris L. The Journal of Heredity, Baltimore, v. 71, p. 218-222, 1980.

SILVA, N. O. Seleção natural e a decisão do melhorista sobre o melhor momento de abrir o "bulk" na cultura do feijoeiro. 2003. 56 p. Dissertação (Mestrado) - Universidade Federal de Lavras, Lavras, 2003.

SINGH, S. P.; GUTIÉRREZ, J. A. Geographical distribution DL 1 and DL 2 genes causing hybrid dwarfism in Phaseolus vulgaris L., their association with seed size, and their significance to breeding. Euphytica, Wageningen, v. 33, p. 337-345, 1984.

SINGH, S. P.; GEPTS, P.; DEBOUCK, D. G. Races of common bean (Phaseolus vulgaris, Fabaceae). Economic Botany, New York, v. 45, n. 3, p. 379-396, July/Sept. 1991.

SINGH, S. P.; URREA, C. A. Inter and intra racial hybridization and selection for seed yield in yearly generations of common bean, Phaseolus vulgaris L. Euphytica, Wageningen, v. 81, n. 2, p. 131-137, June 1995.

SOUZA JÚNIOR, C. L. Componentes da variância genética e suas implicações no melhoramento vegetal. Piracicaba: FEALQ, 1989. 134 p.

VIEIRA, A. L.; RAMALHO, M. A. P.; SANTOS, J. B. Crossing incompatibility in some bean cultivars utilized in Brazil. Revista Brasileira de Genética, Ribeirão Preto, v. 12, n. 1, p. 169-171, 1989.

VILARINHO, L. B. O. Cultivares-ponte de feijoeiro, resistência à mancha angular e mapeamento de QTLs. 2004. 81 f. Tese (Doutorado) - Universidade Federal de Viçosa, Viçosa, 2004. 